\title{
Improvement in Layout Design using SLP of a small size manufacturing unit: A case study
}

\author{
${ }^{1}$ Chandra Shekhar Tak, ${ }^{2}$ Mr.Lalit Yadav \\ ${ }^{I}$ Senior Lecturer Mechanical Engineering, Govt. Polytechnic College, Rajsamand (Raj.) \\ ${ }^{2}$ Assistant Professor,Department of Mechanical Engineering Mewar University, Chittorgarh (Rajasthan)
}

\begin{abstract}
The paper presents an application of the SLP (System Layout Planning) method for establishing, in an efficient manner, the layout of a productive enterprise. A case study is described in the paper, referring to a factory designated for manufacturing steel almirah. The phases of the SLP method application are described in the paper together with the presentation of one particular product given as example. The optimal solution of the productive system's layout is selected by analyzing three possible identified alternatives.
\end{abstract}

Keywords: Facilities layout design, Systematic Layout Planning (SLP), Optimisation

1.1

\section{Introduction}

Plant layout

The efficiency of production depends on how well the various machines; production facilities and employee's amenities are located in a plant. Only the properly laid out plant can ensure the smooth and rapid movement of material, from the raw material stage to the end product stage. Plant layout encompasses new layout as well as improvement in the existing layout. It may be defined as a technique of locating machines, processes and plant services within the factory so as to achieve the right quantity and quality of output at the lowest possible cost of manufacturing. It involves a judicious arrangement of production facilities so that workflow is direct.

\subsection{Definition}

A plant layout can be defined as follows: Plant layout refers to the arrangement of physical facilities such as machinery, equipment, furniture etc. with in the factory building in such a manner so as to have quickest flow of material at the lowest cost and with the least amount of handling in processing the product from the receipt of material to the shipment of the finished product. According to Riggs, "the overall objective of plant layout is to design a physical arrangement that most economically meets the required output - quantity and quality." According to J. L. Zundi, "Plant layout ideally involves allocation of space and arrangement of equipment in such a manner that overall operating costs are minimized.

\subsection{Importance}

Plant layout is an important decision as it represents long-term commitment. An ideal plant layout should provide the optimum relationship among output, floor area and manufacturing process. It facilitates the production process, minimizes material handling, time and cost, and allows flexibility of operations, easy production flow, makes economic use of the building, promotes effective utilization of manpower, and provides for employee's convenience, safety, comfort at work, maximum exposure to natural light and ventilation. It is also important because it affects the flow of material and processes, labour efficiency, supervision and control, use of space and expansion possibilities etc.

\subsection{Essentials}

An efficient plant layout is one that can be instrumental in achieving the following objectives:

a) Proper and efficient utilization of available floor space

b) To ensure that work proceeds from one point to another point without anydelay

c) Provide enough production capacity.

d) Reduce material handling costs

e) Reduce hazards to personnel

f) Utilise labour efficiently

g) Increase employee morale 
h) Reduce accidents

i) Provide for volume and product flexibility

j) Provide ease of supervision and control

k) Provide for employee safety and health

1) Allow ease of maintenance

m) Allow high machine or equipment utilization

n) Improve productivity

\subsection{Types Of Layout}

As discussed so far the plant layout facilitates the arrangement of machines, equipment and other physical facilities in a planned manner within the factory premises. An entrepreneur must possess an expertise to lay down a proper layout for new or existing plants. It differs from plant to plant, from location to location and from industry to industry. But the basic principles governing plant layout are more or less same. As far as small business is concerned, it requires a smaller area or space and can be located in any kind of building as long as the space is available and it is convenient. Plant layout for Small Scale business is closely linked with the factory building and built up area main.:types of layout
(a) Product or line layout
(b) Process or functional layout
(c) Fixed position or location layout
(d) Combined or group layout

\section{Systematic Layout Planning}

SLP is an acronym of Systematic Layout Planning which is a technique established by Richard Muther. (Muther, 1961) It is a step-by-step planning procedure allowing users to identify, visualize, and rate the various activities, relationships, and alternatives involved in a layout project. The three fundamental areas of the technique are relationships, space and adjustment. The sub-contents of the relationship area are collection of input data, flow of materials, activity of relationships and relationship diagrams. The sub-contents of the space area are space requirements, space available and space relationship diagrams. The sub-contents of adjustment area are modifying considerations, practical limitations and evaluation and final selection. This technique combines quantitative measurement of materials movement with non-flow considerations such as noise, fumes, temperature, supervision, communications, personnel comfort and movement. Its major advantage is that it clearly documents the logic of the layout and easily allows input from all levels of staff.

\subsection{Five Important Elements}

The basis and entry points for the research of plant layout problems can be generalized into five important elements according to the SLP method. These five elements are the "key" to the solution. They are:

\section{P-product}

The product element includes the end product, raw materials, machining components and projects of the service. All the information is provided by 10 the production guideline and design menu. This element is the key factor affects the composition and relationship of all the facilities, equipment categories and material handling way.

\section{Q-quantity}

The quantity element indicates the amount of production, supply, utilization or service workload. All the information is provided by production statistics and design menu, and represented by piece, weight, volume and price. This element affects the layout scale, equipment amount, handling workload and construction area.

\section{R-route}

In fact, the route element is the achievement of technological process design. It can be represented by plant layout diagram, process route diagram, process flow chart and so on. It affects the relationship among every work unit, material handling route and warehouse and store location.

\section{S-supporting service}

The service element indicates public and ancillary service which includes tools, maintenance, propulsion, deliveries, and certain railway lines, health stations, changing rooms, canteens and toilets. This kind of element is provided by professional designers from each specific field. The service department supports the production system and somehow reinforces the production efficiency. The area of service department can be larger than the area of production department sometimes. 


\section{T-time}

The time element refers to when and how long the production is, in which includes the operating time of every procedure. According to the time 11 requirement, we can estimate the amount of the equipment, required area and the number of staff Certainly, besides the above five elements, the other related ones are needed to be gathered to finish the final layout design as well. But $\mathrm{P}$ and $\mathrm{Q}$ are the basis for any other characteristics, conditions and elements. To get the most optimal system layout design, it is necessary to firstly make a structured and detailed analysis and calculation according to the comprehensive and accurate original data of these five elements. Then draw a variety of forms, mathematical and graphical models based on the calculation to present the core idea in an easy, obvious and clear way.

\subsection{Stage Structure}

The structure of the SLP method is divided into four stages which are shown in the following.

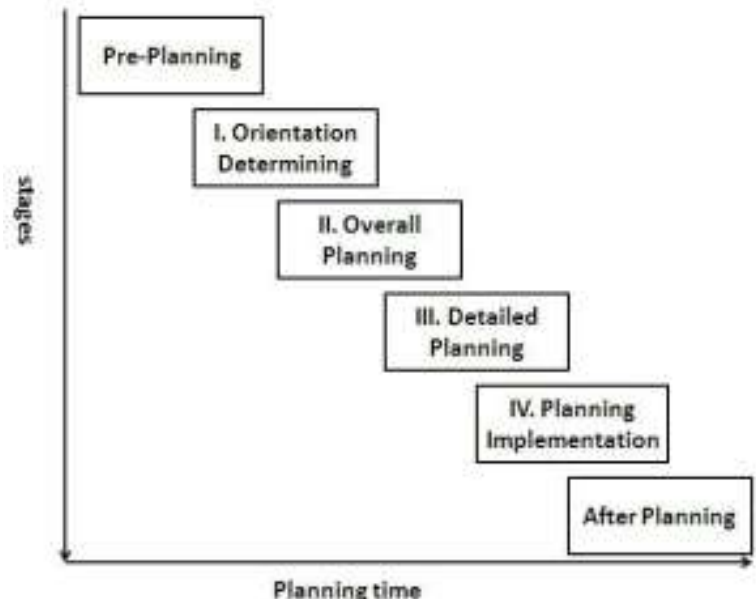

FIGURE 1: SLP stage structure (Adopted from Muther, 1961, SLP)

\section{Stage I. Orientation determining}

The aim of this stage is determining the initial orientation. No matter the overall layout of the whole factory and the layout of every workshop, the appropriate location is needed to be determined first. It is very important to find a correct and suitable location and contribution direction.

\section{Stage II. Overall planning}

After ensuring the circumscription, an overall layout should be planned in this area. The layout should be combined with the basic logistics models and zoning arrangement. To draw a preliminary zoning map, the shape of every operating unit is needed as very important data. It is necessary to know the relationship between every operating unit as well.

\section{Stage III. Detailed Planning}

This planning task should be very detailed for every workshop, work unit and equipment. To obtain the detailed layout, exact facility locations, aisle structures, input/output (I/O) point locations, and the layout with each department should be specified.

\section{Stage IV. Planning implementation}

As the name implies, the main job for this stage is making a construction plan, preparing for the construction, implementing the construction and installation.

In addition, the planning and design department should be responsible for stages II and III. There is crossover among the sequences of these four stages. For example, for the small scale factories which need only one or two workshops, it is feasible to implement the construction accompanies with the planning or modification. Sometimes this crossover can be even more economic and efficient. Anyway, the results of each stage should be approved by higher authorities. The sources and information needed for every stage will become deeper and more complicated along with the stage progress.

Furthermore, before stage I, there is a pre-planning period which is used to determine the objectives, forecast the requirements of facilities and estimate the production capacity and demand. After stage IV, there is the actual final stage which will present the test running of the whole layout after all the implementation. The 
main task during this period is making the conclusion and management summary for the construction, installation and commissioning of the whole project.

\subsection{Procedures}

The methodology is summarized in graph format in Figure 2 which is created originally from Richard Muther and simplified by the following researchers such as Gómez. The overall procedures are consisted by three parts which are analysis, search and selection.

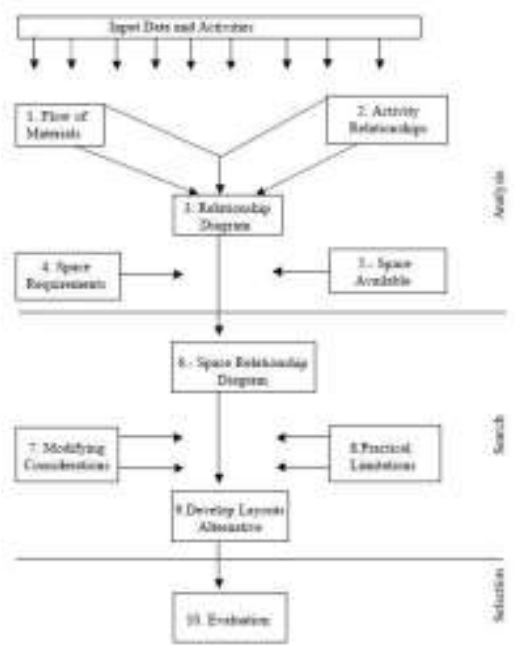

FIGURE 2. SLP method procedures (Gómez, 2003, 271-282)

The first phase of the SLP method involves using a from - to matrix to describe an interdepartmental material flow. In order to do this, a unit of measurement about material handling must have been decided firstly. So the products with different characteristics can be homogenized and comparisons are feasible. Then the REL chart which means the relationship diagram should be made. This chart collects the qualitative information of 'proximity ratios' which consist of a set of letters (A, E, I, O, U, X). They reflect how necessary is for every two work units to be adjacent in the final layout (ranging from A which means 'absolutely necessary' through to $\mathrm{X}$ which shows 'not desirable').

The following step is space analysis which includes availability and requirements. Space availability consists about the actual facility layout where the different work units should be placed. Space requirements are focus on the necessary production parameters such as staff, equipments and others from a theoretical analysis. Comparison and combination of space availability and requirements will provide the actual area to be assigned to each work unit. As a result of analysis process, the space relationship diagram is emerged based on the above space analysis.

After the space relationship diagram is built up, the designers have to remodel or modify the previous design to a greater or lesser extent. Therefore, certain factors which might affect the following implementation of the layout should be taken into account. These factors include various aspects like natural light in the facility, roof heights, the position of electricity points and doors, and the inclusion of aisles for staff, material and equipment movements and so on. Additionally, the practical limitations and modifications which are researched in step 7 and 8 are highly dependent on the empirical skill knowledge and the subjectivity of the person who is responsible for the layout.

In the final analysis, again it is dependent on the design person's experience and opinions to determine how the new information or sources affect the modified layout of the different sections.

\section{Case study}

Case study is conducted at Rajasthan Steel Industries (RSI) Chittorgarh. This company produces steel almirah at its manufacturig facility which is situated at Chamtikheda in Chittorgarh.the company sells its products through its own showroom which is situated in chittorgarh.RSI main production shop which is situated in Chamtikheda is of $60^{\prime} \times 40^{\prime}$ in size.

The machines which are used in producing steel almirah are

1.shearing machine

folding machine

machine 


\subsection{The main process and their sequence}

6.bench grinder machine

7.flexible grinder

8.portable drilling machine

1.cutting operations

pressing and folding operations

operations

4.fitting operations

3.welding

5.painting and coating operations

6.glassfitting and packing

\subsection{Present Layout}

Presently the major operations like cutting, pressing and folding, welding and fitting are performed in the one area of building which is approximately $30 X 30$ size. Although company have sufficient space to locates individual operations in separate areas. But according to company due to unavailability of skilled staff, intermittent order flow it is unable to arrange separate areas for each operations.

Due to lack of systematic layout various problems which were encountered by company

a) Unefficient utilization of available floor space

b) Delay in operations as same floor space is used

c) Unefficient utilization of production capacity.

d) Increase in material handling costs

e) Increase hazards to personnel

f) Unable to utilise labour efficiently

h) Increasing chances of accidents

i) Volume and product un flexibility

j) Difficulty in supervision and control

k) Employee safety and health problems

1) Maintenance difficulties

m) Poor equipment utilization

n) Reduction in productivity

These all factors leads to lower the productivity and consequently increases the final cost of its product. Since the competition in steel furniture industry is very tough. If company reduces its product cost by adopting good and systematic layout ,this will make the product more competitive in market and increase its marketshare.

\section{Analysis \& Result}

Systematic layout planning study of the company have following steps.

1.Calculate the total area available with company which is 2400 square feet.

2.Major operations performed and their sequence.

3. Area required to performs each operation.

4.Propose layout arrangement considering sequence of operation and area constrain.

5.Evaluate each alternative in relation to involved factors like ease in material handling,safety, supervision and control etc.

6.Select from the alternatives the one which have highest score.

Step1 The land available with company is of 60x40 size i.e.2400sq.feet area which is available for actual construction is $90 \%$ of that i.e. 2160 sq.feet.

Step 2\&3

\begin{tabular}{|ll|c|c|}
\hline \multicolumn{1}{|c|}{ Department / Place } & Dimension feet & Area sq. feet \\
\hline 1. & Cutting operations & $30 \times 15$ & 450 \\
\hline $2 . \quad$ Pressing and folding operations & $21 \times 22$ & 462 \\
\hline $3 . \quad$ Welding operations & $14 \times 22$ & 308 \\
\hline $4 . \quad$ Fitting operations & $17 \times 12$ & 204 \\
\hline $5 . \quad$ Painting and coating operations & $13 \times 11$ & 143 \\
\hline 6. & Glass fitting and packing & $11 \times 11$ & 121 \\
\hline
\end{tabular}

Total area required 1688 sq.feet

Table 1. Sequence of operation and required area 
Knowing the space necessities for each one of the involved activities, the total needed area must be compared to the available land surface. In the considered case dimensions of the available land surface is 2160 sq. feet so there exist enough space for build the intended layout in the limits of considered location.

\section{Step 4}

Accordingly to the routes and activities relational diagrams, previously obtained and mentioned above, there have been proposed different alternatives of layout Three of such proposed alternative solutions are shown in Fig.

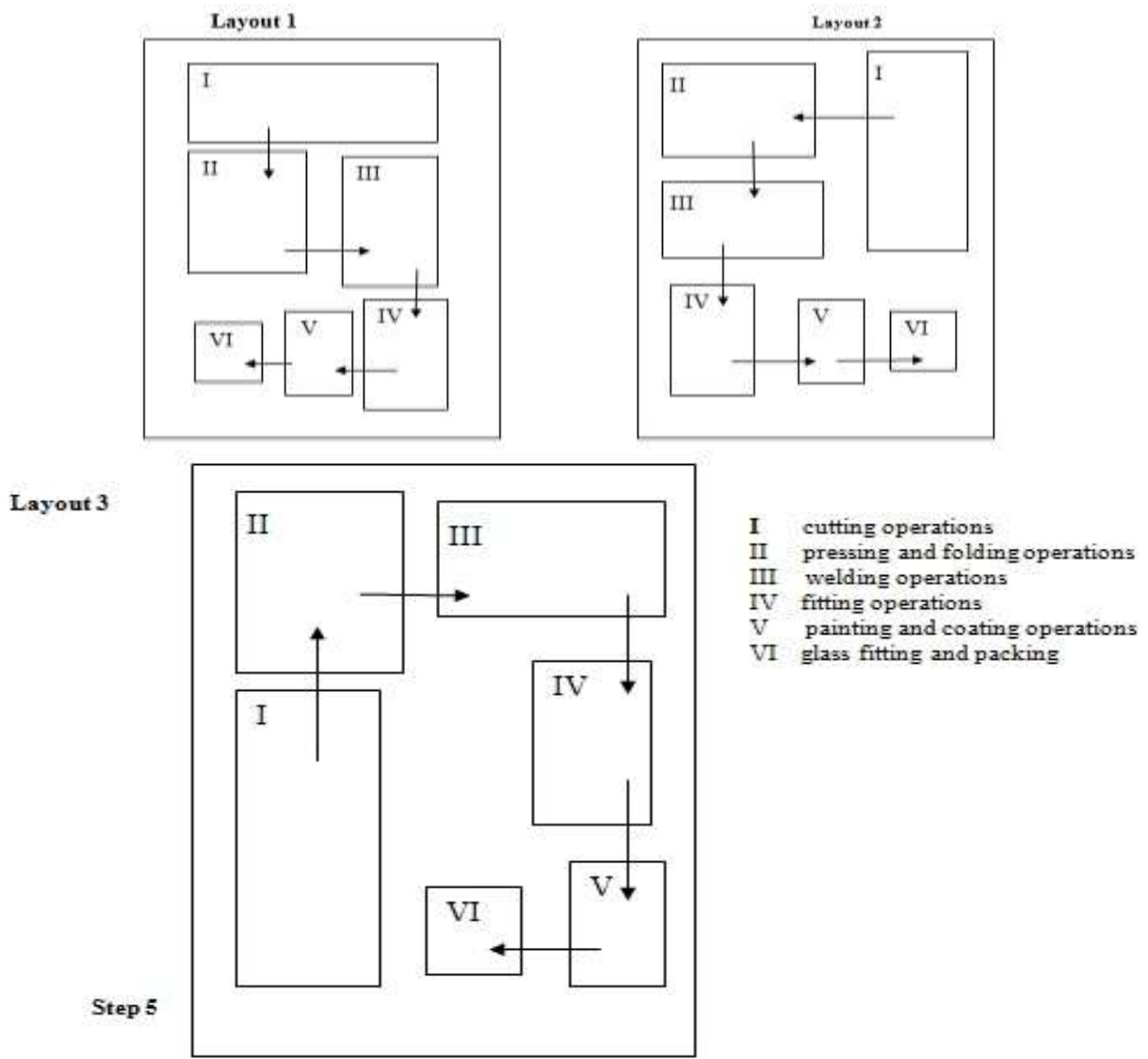

In order to select the optimal alternative solution for the productive enterprise's layout, an evaluation for each of the alternatives, in relation with all the involved factors, was developed.

The main factors that have been considered to identify the optimal layout distribution, together with their weight values, are presented in Table 2

\begin{tabular}{|l|c|}
\hline \multicolumn{1}{|c|}{ Factors } & Weight \\
\hline Growth easiness & 2 \\
\hline Materials flow easiness & 6 \\
\hline Optimum use of the space & 6 \\
\hline Safety & 5 \\
\hline Facility of control and supervision & 3 \\
\hline Facility of installations maintenance & 2 \\
\hline Flexibility of the factory plan & 2 \\
\hline Proximity of places with workers or machine shared & 5 \\
\hline Working conditions & 4 \\
\hline
\end{tabular}

\section{Table 2. The considered factors and their weight}

The weight of each factor took value from 1 to 10 and has been assigned accordingly to the importance given to them, in correspondence to the agreement levels and the point awarded, as it can be seen in Table. 3 


\begin{tabular}{|c|c|}
\hline Agreement Level & Points \\
\hline Poor & 0 \\
\hline Regular & 1 \\
\hline Good & 2 \\
\hline Excellent & 3 \\
\hline
\end{tabular}

Table 3. Points awarded for agreement levels

\section{Step 6}

In Table 4 there are presented the evaluation data for the three alternatives, considering the selected factors and their weights.

\begin{tabular}{|l|c|c|c|}
\hline \multirow{2}{*}{ Factors } & \multicolumn{3}{c|}{ Points/Alternatives } \\
\cline { 2 - 4 } & 1 & 2 & 3 \\
\hline Growth easiness & 2 & 1 & 2 \\
\hline Materials flow easiness & 2 & 1 & 3 \\
\hline Optimum use of the space & 2 & 2 & 2 \\
\hline Safety & 1 & 1 & 2 \\
\hline Facility of control and supervision & 2 & 1 & 1 \\
\hline Facility of installations maintenance & 1 & 2 & 1 \\
\hline Flexibility of the factory plan & 2 & 2 & 2 \\
\hline Proximity of places with workers or machine shared & 2 & 1 & 2 \\
\hline Working conditions & 2 & 2 & 2 \\
\hline Total Result & 63 & 49 & 71 \\
\hline
\end{tabular}

Table 4. Evaluation and selection of the three proposed alternatives

Result

From the obtained evaluation data, there can be seen that the alternative with the best score is the alternative no. 3, so this alternative will represent the plant layout that must be used for the intended factory.

\section{CONCLUSION}

The paper presents an application of the SLP (System Layout Planning) method for establishing, in an efficient manner, the layout of a productive enterprise. A case study is described in the paper, referring to a factory designated for manufacturing steel almirah The phases of the SLP method application are described in the paper, together with the presentation of one particular products given as example. The optimal solution of the productive system's layout is selected by analyzing three possible identified alternatives.

The case study of SLP at this company illustrate that small and medium firms can successfully layout and re-layout their facilities with this easy to use technique. The results arrived from SLP does not completely satisfy all but it clearly shows why decisions are made. This study shows that SLP process was as valuable as the final layout .

\section{References}

[1] Banerjee P., Zhou Y. (1995), Facilities layout design optimization with single loop material flow path configuration; Int. Journal of Production Research 33(1); 183-204.

[2] Banerjee P., Zhou Y., Montreuil B. (1997),Genetically assisted optimization of cell layout andmaterial flow path skeleton; IIE Trans 29(4); 277-292.Layout Design of a Furniture... 95

[3] Bozer Y.A, Meller R.D., Erlebacher S.J. (1994), An improvement type layout algorithm;International Journal of Production Research 1; 1675-1692.

[4] Buffa E.S., Armour G.C., Vollman T.E. (1964), Allocating facilities with CRAFT; Harvard BusinessReview 42; 136159.

[5] De-Alvarenga A.G., Gomes N.J., Mestria M. (2000), Metaheuristic methods for a class of the facilitylayout problems; Journal of Intelligent Manufacturing 11; 421-430.

[6] Domschke W., Drexl A. (1985), Location and layout planning, An international bibliography;Springer Verlag, Berlin.

[7] Foulds L.R., Robinson D.F. (1976), A strategy for solving the plant layout problem; OperationalResearch Quarterly 27; 845-855.

[8] Francis R.L., McGinnis Jr. L.F., White J.A. (1992), 2nd Ed, Facility layout and location, An analytical approach; Prentice Hall; Englewood Cliffs, NJ.

[9] Fu M.C., Kaku B.K. (1997), Minimizing work in progress and material handling in the facilitieslayout problem; IIE Trans 29; 29-36.

[10] Giffin J.W., Foulds L.R. Cameron D.C. (1984), Drawing a block plan from a REL chart with graph theory and microcomputer; Computers \& Industrial Engineering 10; 109-116.

[11] Green R.H., Al-Hakim L. (1985), A heuristic for facilities layout planning; OMEGA, InternationalJournal of Management Science 13; 469-474.

[12] Hassan M.M.D., Hogg G.L. (1991), On constructing a block layout by graph theory; 